\title{
Determinants of alcohol consumption and marijuana use among young adults in the Republic of Palau
}

\author{
Mizuki Sata ${ }^{1,2}$, Renzhe Cui ${ }^{1}$, Chifa Chiang ${ }^{3}$, Singeru Travis Singeo $\mathrm{Jr}^{4}$, Berry Moon Watson ${ }^{4}$, Hiroshi Yatsuya ${ }^{3,5}$, \\ Kaori Honjo ${ }^{1,6}$, Takashi Mita ${ }^{7}$, Everlynn Joy Temengil ${ }^{4}$, Sherilynn Madraisau ${ }^{4}$, Kazumasa Yamagishi, \\ Atsuko Aoyama ${ }^{3}$ and Hiroyasu Iso ${ }^{1 *}$ (D)
}

\begin{abstract}
Background: This study aimed to describe the status of alcohol consumption and drug use among young adults as well as their determinants.

Methods: We conducted a cross-sectional study of 356 young adults (aged 18 to 24 years) living in Palau in 2013. The prevalence of self-reported alcohol and marijuana usage were compared within and between sexes, age groups, ethnicities, and education levels.

Results: The proportion of current drinking was higher in people aged $21-24$ than in those aged $18-20$ (73.2\% vs. $60.9 \%, p=0.09$ in men and $48.3 \%$ vs. $30.0 \%, p=0.02$ in women), while that of marijuana use did not differ between the age groups. The proportions of current drinking and marijuana use were higher in Palauan than in other ethnicities (current drinking: $70.6 \%$ vs. $40.6 \%, p=0.005$ in men and $38.8 \%$ vs. $16.6 \%, p=0.04$ in women; lifetime marijuana use: $80.0 \%$ vs. $52.9 \%, p=0.02$ in men and $56.1 \%$ vs. $30.6 \%, p=0.09$ in women). The proportion of frequent ( 3 times or more) marijuana users was higher for the lower educated than for the higher educated ( $62.5 \%$ vs. $32.1 \%, p<0.001$ in men and $33.9 \%$ vs. $24.4 \%, p=0.12$ in women).
\end{abstract}

Conclusions: Sex, age, ethnicity, and education were significant determinants of alcohol and marijuana use.

Keywords: Non-communicable disease, Alcohol, Drug, Palau, Pacific islanders

\section{Background}

In 2010, the World Health Organization (WHO) published a global strategy to reduce the harmful use of alcohol which is a significant contributor to the global burden of disease and is listed as the third leading risk factor for premature deaths and disabilities in the world [1]. It is estimated that 3.3 million people worldwide died of alcohol-related causes, corresponding to $5.9 \%$ of all deaths in 2012 [2]. With regard to patterns of alcohol

\footnotetext{
* Correspondence: iso@pbhel.med.osaka-u.ac.jp

${ }^{1}$ Public Health, Department of Social Medicine, Osaka University Graduate School of Medicine, 2-2 Yamadaoka, Suita, Osaka 565-0871, Japan Full list of author information is available at the end of the article
}

consumption, monthly heavy episodic drinking was slightly more prevalent among young people between 15 and 19 years of age (11.7\%) than among the total population aged 15 years or older (7.5\%) [2].

As for the most serious outcome that can result from illicit drug use, it is estimated that 187,100 drug-related deaths occurred worldwide $(40.8 \%$ deaths per million aged 15-64) in 2013 [3]. In addition, 27 million people aged 15-64 are problematic drug users [3].

The Republic of Palau, an island state in Oceania with a population of approximately 20,000, has been reported to have a high burden of non-communicable diseases (NCDs) attributable to lifestyles including alcohol consumption or

(c) The Author(s). 2021 Open Access This article is licensed under a Creative Commons Attribution 4.0 International License, which permits use, sharing, adaptation, distribution and reproduction in any medium or format, as long as you give appropriate credit to the original author(s) and the source, provide a link to the Creative Commons licence, and indicate if changes were made. The images or other third party material in this article are included in the article's Creative Commons licence, unless indicated otherwise in a credit line to the material. If material is not included in the article's Creative Commons licence and your intended use is not permitted by statutory regulation or exceeds the permitted use, you will need to obtain permission directly from the copyright holder. To view a copy of this licence, visit http://creativecommons.org/licenses/by/4.0/. The Creative Commons Public Domain Dedication waiver (http://creativecommons.org/publicdomain/zero/1.0/) applies to the data made available in this article, unless otherwise stated in a credit line to the data. 
drug use, as with another countries in Micronesia [4]. In general, a meta-analysis that included nine studies (USA, UK, New Zealand, Finland, and Italy) showed that lower socioeconomic status was associated with higher prevalence of alcohol and marijuana use among adolescents aged 1015 years [5]. The Youth Risk Behavior Surveillance System (YRBSS) found that $66.2 \%$ of Palauan high school students have previously consumed alcohol, $37.4 \%$ were currently consuming alcohol, $66.3 \%$ have previously used marijuana, and $38.4 \%$ were currently using marijuana [6]. However, whether student habits become worse or better after graduation remains unclear. Therefore, in this study, our aim was to investigate the prevalence of alcohol and marijuana use and their social and demographic determinants among young adults living in Palau.

\section{Methods}

\section{Study subjects}

This is a cross-sectional study involving the youth population from ages 18 to 24 years living in Palau. In October 2013, we established a survey station at Palau Community College (PCC), located in the center of Koror, since PCC is the only college-level education institution in Palau, provides optimum geographic access, and is the sole organization with a majority of members in the target age group (473 students). In order to reach as many potential participants as possible, we also dispatched a mobile survey team to a few local communities and major employers in Koror. A total of 356 people (310 Palauan and 46 nonPalauan) voluntarily participated in the survey. After excluding volunteers with missing answers for drug use ( $n$ $=1)$, a 17-year-old participant $(n=1)$, and pregnant women $(n=2)$, data from the remaining 352 participants (174 men, 178 women) were analyzed. None of the analyzed surveys had missing answers with regards to alcohol consumption.

The study protocol was reviewed and approved by the Osaka University Research Committee (approval number: 12145), the Nagoya University School of Medicine Bioethics Review Committee (approval number: 2012-0103), and the Institutional Review Board of the Ministry of Health, Republic of Palau. Written, informed consent was obtained from all of the participants prior to the study.

\section{Measurement and classification of variables}

The questionnaire administered to participants consisted of lifestyle questions such as tobacco use, alcohol consumption, diet, physical inactivity, education level, household income, mental health, sleep habits, and illicit drug use. The details of the protocol used in this study are described elsewhere [7]. In brief, the questionnaire asked about alcohol consumption (ever consumed, consumed during the past 12 months, frequency of alcohol consumption during the past 12 months, and consumed during the past 30 days), marijuana use (past usage, age at the first use, and use during the past 30 days), ethnicity (Palauan, Filipino, or Other), and education (less than primary, primary completed, secondary school completed, and college/university completed).

\section{Statistical analysis}

Calculation of the Kappa coefficient was used to assess correlations between current drinking (yes/no) and marijuana usage (yes/no) during the past month prior to the survey. Differences in proportions of alcohol and/or marijuana usage with respect to sex (men vs. women) and age groups (18 to 20 years old vs. 21 [legal drinking age in Palau] to 24 years old) were tested by analysis of variance (ANOVA). Sex-specific, and age-adjusted proportions for each outcome according to ethnicities (Palauan vs. others) and education levels (low: secondary school completed or less vs. high: college/university completed or more) were examined using analysis of covariance (ANCOVA). Differences in the distributions of the frequency of alcohol consumption during the 12 months prior to surveying and marijuana use between sexes and two age groups were analyzed by Chi-squared testing. Mantel-Haenszel tests were used for differences in the age-adjusted distributions of ethnicities and education levels.

All statistical analyses were performed with SAS version 9.4 software (SAS Institute, Inc., Cary, NC, USA). All probability values for statistical tests were two-tailed and values of $p<0.05$ were regarded as statistically significant.

\section{Results}

A total of 352 individuals (306 Palauan and 46 nonPalauan) between 18 and 24 years of age with a mean age of 20.2 years, voluntarily participated in the survey. In total, $37.9 \%$ of men and $39.1 \%$ of women were found to be currently drinking alcohol and using marijuana. Concurrent alcohol and/or marijuana use were positively correlated (kappa coefficient $=0.2468 ; p<0.001$ ). Sexspecific characteristics are presented in Table 1 . Most of participants were aged 18-20 years, Palauans, and mostly with low education level. The proportion of current smoking was $40.8 \%$ in men and $11.8 \%$ in women.

As shown in Table 2, 93.1\% of men and $73.6 \%$ of women had previously consumed alcohol, and $66.7 \%$ of men and $36.0 \%$ of women had consumed alcohol within 30 days before the survey while $76.4 \%$ of men and $52.8 \%$ of women had previously used marijuana and $32.8 \%$ of men and $19.7 \%$ of women had used marijuana within 30 days before the survey.

The proportion of current alcohol drinking was higher in the age 21-24 category than the age 18-20 category (73.2\% vs. $60.9 \%, p=0.09$ in men and $48.3 \%$ vs. $30.0 \%, p$ $=0.02$ in women) as shown in Table 3 . The respective 
Table 1 Sex-specific characteristics among 352 individuals between 18 and 24 years of age in Palau, 2013

\begin{tabular}{lll}
\hline & $\begin{array}{l}\text { Men } \\
(\boldsymbol{n}=\mathbf{1 7 4})\end{array}$ & $\begin{array}{l}\text { Women } \\
(\boldsymbol{n}=\mathbf{1 7 8})\end{array}$ \\
\hline Age & 52.9 & 67.4 \\
18-20 years old, \% & 47.1 & 32.6 \\
21-24 years old, \% & & \\
Ethnicity & 86.8 & 87.1 \\
$\quad$ Palauans, \% & 13.2 & 12.9 \\
$\quad$ Non-Palauans, \% & & \\
Education level & 24.1 & 25.3 \\
$\quad$ High, \% & 75.9 & 74.7 \\
$\quad$ Low, \% & 40.8 & 11.8 \\
\hline
\end{tabular}

proportions among Palauans aged 18-20 years were $90.7 \%$ in men and $75.7 \%$ in women (data not shown). The proportion of marijuana use did not differ by age groups. As shown in Fig. 1, 37.4 \% of men started marijuana at under 14 years old while $24.7 \%$ of women started under 14 years old.

In Table 4, the proportion of current drinking was higher in Palauans than the non-Palauans $(70.6 \%$ vs. $40.6 \%, p=0.005$ in men and $38.8 \%$ vs. $16.6 \%, p=0.04$ in women). The proportion of Palauans who had ever used marijuana was higher than in non-Palauans $(80.0 \%$ vs. $52.9 \%, p=0.02$ in men and $56.1 \%$ vs. $30.6 \%, p=0.09$ in women).

As shown in Table 5, a low education level was associated with increased lifetime marijuana use in men. A similar but non-significant trend was observed in women. Educational levels were not associated with alcohol consumption in either sex. The proportion of men who used marijuana 3 or more times was higher in the low education group than in the high education group $(62.5 \%$ vs. $32.1 \%, p<0.001)$. The corresponding proportion of women tended to be higher in the low education group than in the high education group, but the difference was not statistically significant $(33.9 \%$ versus $24.4 \%, p=0.12$ ).

\section{Discussion}

We found a high prevalence of alcohol and marijuana use among Palauan men and women aged 18-24 years. Among young adults living in Palau, sex, age, ethnicity, and education level were significant determinants of alcohol or marijuana use. As far as we know, this is the first study to identify demographic and social determinants (sex, age, ethnicity, and education level) of alcohol consumption and marijuana use among Palauans aged 18 to 24 years.

We found that $51.4 \%$ (66.7\% of men and $36.0 \%$ of women) aged 18 to 24 years reported alcohol drinking

Table 2 Sex-specific proportions of alcohol consumption and marijuana use

\begin{tabular}{|c|c|c|c|}
\hline & $\begin{array}{l}\text { Men } \\
(n=174)\end{array}$ & $\begin{array}{l}\text { Women } \\
(n=178)\end{array}$ & $P$ value \\
\hline \multicolumn{4}{|l|}{ Alcohol consumption } \\
\hline Ever consumed, \% & 93.1 & 73.6 & $<0.001^{* * *}$ \\
\hline Consumed alcohol during the past 12 months, $\%$ & 81.0 & 57.3 & $<0.001^{* * *}$ \\
\hline Frequency of alcohol consumption during the past 12 months, \% & & & $0.004^{* *}$ \\
\hline Daily & 1.7 & 0.6 & \\
\hline 5-6 days per week & 4.6 & 0.6 & \\
\hline 1-4 days per week & 21.3 & 6.7 & \\
\hline 1-3 days per month & 32.8 & 25.3 & \\
\hline Less than once a month & 39.7 & 66.9 & \\
\hline Consumed alcohol during the past 30 days, $\%$ & 66.7 & 36.0 & $<0.001^{* * *}$ \\
\hline \multicolumn{4}{|l|}{ Marijuana use } \\
\hline Lifetime marijuana use, \% & & & $<0.001^{* * *}$ \\
\hline Non & 23.6 & 47.2 & \\
\hline 1 or 2 times & 21.3 & 21.3 & \\
\hline 3 or more times & 55.1 & 31.5 & \\
\hline Marijuana use during the past 30 days, $\%$ & & & $0.005^{* *}$ \\
\hline No & 67.2 & 80.3 & \\
\hline Yes & 32.8 & 19.7 & \\
\hline
\end{tabular}

${ }^{* *} p<0.01 ;{ }^{* *} p<0.001$ 
Table 3 Sex- and age-specific proportions of alcohol consumption and marijuana use

\begin{tabular}{|c|c|c|c|c|c|c|}
\hline \multirow[t]{2}{*}{ Age groups } & \multicolumn{3}{|l|}{ Men } & \multicolumn{3}{|l|}{ Women } \\
\hline & $\begin{array}{l}18-20 \\
(n=92)\end{array}$ & $\begin{array}{l}21-24 \\
(n=82)\end{array}$ & $\begin{array}{l}\text { P for } \\
\text { difference }\end{array}$ & $\begin{array}{l}18-20 \\
(n=120)\end{array}$ & $\begin{array}{l}21-24 \\
(n=58)\end{array}$ & $\begin{array}{l}P \text { for } \\
\text { difference }\end{array}$ \\
\hline \multicolumn{7}{|l|}{ Alcohol consumption } \\
\hline Ever consumed, \% & 90.2 & 96.3 & 0.11 & 70.0 & 81.0 & 0.12 \\
\hline Consumed alcohol during the past 12 months, $\%$ & 78.3 & 84.1 & 0.33 & 51.7 & 69.0 & $0.03^{*}$ \\
\hline $\begin{array}{l}\text { Frequency of alcohol consumption during the } \\
\text { past } 12 \text { months, } \%\end{array}$ & & & 0.05 & & & 0.32 \\
\hline Daily & 0 & 3.7 & & 0.8 & 0 & \\
\hline 5-6 days per week & 1.1 & 8.5 & & 0 & 1.7 & \\
\hline 1-4 days per week & 20.7 & 22.0 & & 5.8 & 8.6 & \\
\hline $1-3$ days per month & 32.6 & 32.9 & & 20.0 & 36.2 & \\
\hline Less than once a month & 45.7 & 32.9 & & 73.3 & 53.4 & \\
\hline Consumed alcohol during the past 30 days, $\%$ & 60.9 & 73.2 & 0.09 & 30.0 & 48.3 & $0.02^{*}$ \\
\hline \multicolumn{7}{|l|}{ Marijuana use } \\
\hline Lifetime marijuana use, \% & & & 0.14 & & & 0.46 \\
\hline Non & 20.7 & 26.8 & & 48.3 & 44.3 & \\
\hline 1 or 2 times & 28.3 & 13.4 & & 20.0 & 24.1 & \\
\hline 3 or more times & 51.1 & 59.8 & & 31.7 & 31.0 & \\
\hline Marijuana use during the past 30 days, $\%$ & & & 0.71 & & & 0.52 \\
\hline No & 68.5 & 65.9 & & 81.7 & 77.6 & \\
\hline Yes & 31.5 & 34.1 & & 18.3 & 22.4 & \\
\hline
\end{tabular}

during the past 30 days. According to the statistics in Palau, one-half of adults were drinkers and the average of 773 cans of standard drinks (beer, wine, and spirits) per adult were imported [8]. The proportions of alcohol drinking during the past 30 days among Americans aged $18-22$ years were $51.6 \%$ of men and $52.0 \%$ of women in 2015 [9]. In England, the proportion who drank alcohol in the last week was $46.9 \%$ and $44.5 \%$ at ages of $16-24$ years in 2013 [10]. The production, sale, and possession of any form of medicinal marijuana products are illegal in Palau; however, we found that $26.3 \%$ (32.8\% of men and $19.7 \%$ of women) aged 18 to 24 years used marijuana during the past 30 days. In the USA, approximately $20 \%$ of young adults aged 18 to 25 used marijuana in 2014 [11], indicating that the prevalence of marijuana use was much higher among young adults in Palau. Furthermore, in the present study, many Palauan youth started to use marijuana. The high usage of alcohol and marijuana in Palauan teens was probably due to their easy retail and social access because alcohol was widely sold and marijuana was often cultivated on private farms [12]. The common use of marijuana may also be due to Palauan cultural acceptance. In 1987, Evans reported from Palau that "It was clear that marijuana was not perceived to be a problem substance by users or law enforcement officers, and marijuana was grown openly in Palau" [13].

The Youth Risk Behavior Surveillance System (YRBSS) for Pacific Island countries found that the proportion of current student drinkers aged 13 to 15 years varied

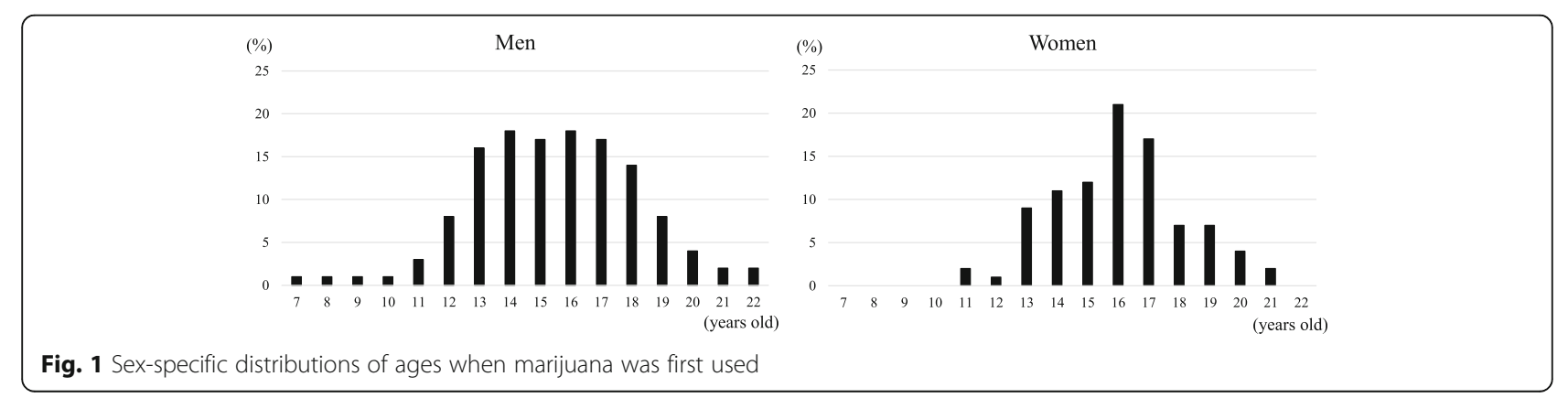


Table 4 Sex-specific and age-adjusted proportions of alcohol consumption and marijuana use by ethnicity

\begin{tabular}{|c|c|c|c|c|c|c|}
\hline \multirow[t]{2}{*}{ Ethnicity } & \multicolumn{3}{|l|}{ Men } & \multicolumn{3}{|l|}{ Women } \\
\hline & $\begin{array}{l}\text { Palauans } \\
(n=151)\end{array}$ & $\begin{array}{l}\text { Non-Palauans } \\
(n=23)\end{array}$ & $\begin{array}{l}P \text { for } \\
\text { difference }\end{array}$ & $\begin{array}{l}\text { Palauans } \\
(n=155)\end{array}$ & $\begin{array}{l}\text { Non-Palauans } \\
(n=23)\end{array}$ & $\begin{array}{l}P \text { for } \\
\text { difference }\end{array}$ \\
\hline \multicolumn{7}{|l|}{ Alcohol consumption } \\
\hline Ever consumed, \% & 94.3 & 85.6 & 0.13 & 79.4 & 34.4 & $<0.001^{* * *}$ \\
\hline Consumed alcohol during the past 12 months, $\%$ & 84.2 & 60.0 & $0.007^{* *}$ & 61.4 & 29.7 & $0.004^{* *}$ \\
\hline $\begin{array}{l}\text { Frequency of alcohol consumption during the } \\
\text { past } 12 \text { months, } \%\end{array}$ & & & 0.37 & & & 0.94 \\
\hline Daily & 2.2 & 0 & & 0.6 & 0 & \\
\hline 5-6 days per week & 5.5 & 0 & & 0.7 & 0 & \\
\hline $1-4$ days per week & 20.5 & 26.3 & & 6.5 & 8.6 & \\
\hline $1-3$ days per month & 35.2 & 16.7 & & 28.5 & 3.6 & \\
\hline Less than once a month & 36.6 & 59.8 & & 63.7 & 87.9 & \\
\hline Consumed alcohol during the past 30 days, $\%$ & 70.6 & 40.6 & $0.005^{* *}$ & 38.8 & 16.6 & $0.04^{*}$ \\
\hline \multicolumn{7}{|l|}{ Marijuana use } \\
\hline Lifetime marijuana use, \% & & & $0.02^{*}$ & & & 0.09 \\
\hline Non & 20.0 & 47.1 & & 43.9 & 69.4 & \\
\hline 1 or 2 times & 21.4 & 20.4 & & 23.2 & 8.9 & \\
\hline 3 or more times & 58.6 & 32.5 & & 32.9 & 21.7 & \\
\hline Marijuana use during the past 30 days, $\%$ & & & 0.78 & & & 0.88 \\
\hline No & 67.0 & 68.9 & & 80.7 & 78.2 & \\
\hline Yes & 31.1 & 33.0 & & 21.8 & 19.3 & \\
\hline
\end{tabular}

${ }^{*} p<0.05 ;{ }^{* *} p<0.01 ;{ }^{* * *} p<0.001$

between $10.3 \%$ and $43.7 \%$ in boys and $5.1 \%$ and $28.7 \%$ in girls [14]. The Global School-Based Health Survey (GSHS) reported similar proportions of current drinkers: $40.6 \%$ in boys and $14.1 \%$ in girls of grades 6 to 10 in four Pacific Island countries [15]. For young adults aged 25 to 64 years, the age-standardized proportions of current drinkers varied more among Pacific Island countries according to the WHO STEPwise approach to surveillance (STEPS): $13.1 \%$ to $96.0 \%$ in men and $1.2 \%$ to $90.1 \%$ in women [14]. In the present study, we found that the proportion of alcohol drinkers in the 30-day period prior to the survey was $66.7 \%$ in men and $36.0 \%$ in women, indicating that habitual alcohol consumption is very common among Palauan adolescents and young adults.

The proportions of those Palauans who had used marijuana before were $68.6 \%$ in boys and $56.9 \%$ in girls of grades 9 to 12 according to the 2013 YRBSS [16]. We found that the proportion of prior marijuana users was $76.4 \%$ in men and $52.8 \%$ in women aged 18 to 24 years. Therefore, marijuana usage among men may become common after students enter college due to peer pressure and easy access.

In the present study, among men, low education was associated with lifetime marijuana use but not with alcohol consumption. According to systematic reviews, childhood social disadvantages, including low education, were associated with risk of cannabis use (but not alcohol use) from adolescence to adulthood $[17,18]$. However, the higher proportion of lifetime marijuana use in the low education group does not necessarily imply that low education per se led to marijuana use since it may be strongly confounded by low family income. Leniency among low-income and low education parents may allow more teenagers or young adults to start marijuana usage [19]. Among women in the preset study, low education tended to be associated with lifetime marijuana use, but the association did not reach statistical significance. A study of 45 men and 48 women aged 8-30 years showed that the magnitude of risk behaviors evaluated by gambling task were higher in men than in women for all age groups [20]. The tendency of taking non-risky behaviors in women could make the association between education and lifetime marijuana use weaker.

The strength of this study is in its clarification of demographic and social determinants (sex, age, ethnicity, and education levels) of alcohol consumption and marijuana use among young adult Palauans. However, there are several limitations in the present study. First, the participation rate of non-PCC students was not high (25\%) and approximately $80 \%$ of the participants lived in Koror. However, we sampled over $20 \%$ of the total 18 to 
Table 5 Sex-specific and age-adjusted proportions of alcohol consumption and marijuana use by education level

\begin{tabular}{|c|c|c|c|c|c|c|}
\hline \multirow[t]{2}{*}{ Education level } & \multicolumn{3}{|l|}{ Men } & \multicolumn{3}{|l|}{ Women } \\
\hline & $\begin{array}{l}\text { High } \\
(n=42)\end{array}$ & $\begin{array}{l}\text { Low } \\
(n=132)\end{array}$ & $\begin{array}{l}P \text { for } \\
\text { difference }\end{array}$ & $\begin{array}{l}\text { High } \\
(n=45)\end{array}$ & $\begin{array}{l}\text { Low } \\
(n=133)\end{array}$ & $\begin{array}{l}P \text { for } \\
\text { difference }\end{array}$ \\
\hline \multicolumn{7}{|l|}{ Alcohol consumption } \\
\hline Ever consumed, \% & 94.7 & 92.6 & 0.65 & 73.0 & 73.8 & 0.91 \\
\hline Consumed alcohol during the past 12 months, $\%$ & 76.0 & 82.6 & 0.35 & 57.0 & 57.4 & 0.96 \\
\hline $\begin{array}{l}\text { Frequency of alcohol consumption during the } \\
\text { past } 12 \text { months, } \%\end{array}$ & & & 0.86 & & & 0.51 \\
\hline Daily & 1.6 & 1.8 & & 0 & 0.7 & \\
\hline 5-6 days per week & 4.2 & 4.7 & & 0 & 0.8 & \\
\hline $1-4$ days per week & 14.1 & 23.5 & & 2.1 & 8.3 & \\
\hline $1-3$ days per month & 33.3 & 32.6 & & 30.3 & 23.6 & \\
\hline Less than once a month & 46.7 & 37.4 & & 67.7 & 66.6 & \\
\hline Consumed alcohol during the past 30 days, $\%$ & 58.4 & 69.3 & 0.20 & 41.4 & 34.1 & 0.38 \\
\hline \multicolumn{7}{|l|}{ Marijuana use } \\
\hline Lifetime Marijuana use, \% & & & $<0.001^{* * *}$ & & & 0.12 \\
\hline Non & 32.7 & 20.7 & & 55.4 & 44.4 & \\
\hline 1 or 2 times & 35.2 & 16.8 & & 20.3 & 21.7 & \\
\hline 3 or more times & 32.1 & 62.5 & & 24.4 & 33.9 & \\
\hline Marijuana use during the past 30 days, $\%$ & & & 0.30 & & & 0.35 \\
\hline No & 73.6 & 65.2 & & 75.4 & 82.0 & \\
\hline Yes & 26.4 & 34.8 & & 24.6 & 18.0 & \\
\hline
\end{tabular}

${ }^{* * *} p<0.001$

24-year-old population living in Palau, of which more than $80 \%$ resided in Koror [7]. Therefore, the impact of selection bias was likely to be negligible. Second, we did not obtain detailed information regarding the amounts and usage patterns of alcoholic beverages and marijuana. Third, the law governing participants' nation may influence on the present results; however, we cannot evaluate that possibility because the detailed information on nationality among non-Palauans was not obtained.

\section{Conclusion}

Sex, age, ethnicity, and education were significant determinants of alcohol or marijuana use among young adults living in Palau, particularly Palauans. This study was executed to serve as a baseline reference for the further development of public health measures to control alcohol and drug use in Palau.

\section{Acknowledgements}

The authors thank staff members of the Health Policy, Research, and Development (HPRD) office and the NCD Unit, Ministry of Health, Republic of Palau for their assistances in the data collection and for providing valuable advice during the survey process. Appreciation is also given to the President, the Dean, and other members of Palau Community College for their great help in preparation of the venue and promotion for the survey. The authors would like to additionally thank Dr. Bryan J. Mathis of the Medical English

Communication Center (Univ. of Tsukuba, Japan) for editing of this manuscript.

\section{Authors' contributions}

MS designed the study, performed the statistical analyses, interpreted the data, and drafted and revised the manuscript. HI supervised the study. RC, CC, SS, BW, HY, KH, TM, ET, SM, KY, and AA supported with the study design, were involved in data collection, and revised the manuscript. All authors read and approved the final manuscript.

\section{Funding}

This study was supported by the Health and Labour Sciences Research Grants for Research on Global Health Issues (H24-chikyukibo-ippan-004) to A.A. from the Ministry of Health, Labour and Welfare, Government of Japan.

\section{Availability of data and materials}

The datasets generated during and/or analyzed during the current study are not publicly available due to ethical consideration.

\section{Ethics approval and consent to participate}

The study protocol was reviewed and approved by the Osaka University Research Committee (approval number: 12145), the Nagoya University School of Medicine Bioethics Review Committee (approval number: 2012-0103), and the Institutional Review Board of the Ministry of Health, Republic of Palau. Written informed consent was obtained from all of the participants prior to the study.

\section{Consent for publication}

Not applicable.

\section{Competing interests}

The authors declare that they have no competing interests.

\section{Author details}

'Public Health, Department of Social Medicine, Osaka University Graduate School of Medicine, 2-2 Yamadaoka, Suita, Osaka 565-0871, Japan.

${ }^{2}$ Department of Preventive Medicine and Public Health, Keio University School of Medicine, 35 Shinanomachi, Shinjuku-ku, Tokyo 160-8582, Japan. 
${ }^{3}$ Department of Public Health and Health Systems, Nagoya University School of Medicine, 65 Tsurumai-cho, Showa-ku, Nagoya, Aichi 466-8550, Japan. ${ }^{4}$ Ministry of Health, Republic of Palau, One Hospital Road, P.O. Box 6027, Koror 96940, Republic of Palau. ${ }^{5}$ Department of Public Health, Fujita Health University School of Medicine, 1-98 Dengakugakubo, Kutsukake-cho, Toyoake, Aichi 470-1192, Japan. ${ }^{6}$ Faculty of Medicine, Social and Behavior Sciences, Osaka Medical College, 2-7 Daigakumachi, Takatsuki, Osaka 569-8686, Japan. ${ }^{7}$ Faculty of International Relations, Kyoto Sangyo University, Motoyama, Kamigamo, Kita-ku, Kyoto, Kyoto 603-8555, Japan. ${ }^{8}$ Department of Public Health Medicine, Faculty of Medicine, and Health Services Research and Development Center, University of Tsukuba, 1-1-1 Tennodai, Tsukuba, Ibaraki 305-8575, Japan.

Received: 24 July 2020 Accepted: 21 December 2020

Published online: 22 January 2021

\section{References}

1. World Health Organization. Global strategy to reduce the harmful use of alcohol. 2010. Available at: https://www.who.int/publications/i/item/ 9789241599931. (Accessed November 2017).

2. World Health Organization. Global Status Report on Alcohol and Health 2014. 2014. Available at: https://apps.who.int/iris/bitstream/handle/1 0665/112736/9789240692763_eng.pdf;jsessionid=1D95855711FFE0B4D1231 B244257FEF6?sequence=1. (Accessed August 2020).

3. United Nations Office on Drugs and Crime. World Drug Report 2015. 2015. Available at: https://www.unodc.org/documents/wdr2015/World_Drug_ Report_2015.pdf. (Accessed August 2020).

4. Murdock D, Salit J, Stoffel M, Friedman JM, Pe'er I, Breslow JL, Bonnen PE. Longitudinal study shows increasing obesity and hyperglycemia in micronesia. Obesity (Silver Spring). 2013;21:E421-7.

5. Lemstra M, Bennett NR, Neudorf C, Kunst A, Nannapaneni U, Warren LM, Kershaw T, Scott CR. A meta-analysis of marijuana and alcohol use by socioeconomic status in adolescents aged 10-15 years. Can J Public Health. 2008; 99:172-7.

6. High School YRBS, Palau 2015 Results. Centers for Disease Control and Prevention. Available at: https://nccd.cdc.gov/youthonline/App/Results. aspx?LID=PW. (Accessed November 2017).

7. Chiang C, Singeo ST Jr, Yatsuya H, Honjo K, Mita T, Ikerdeu E, Cui R, Li Y, Watson BM, Ngirmang G, Iso H, Aoyama A. Profile of non-communicable Disease risk factors among young people in Palau. J Epidemiol. 2015;25: 392-7.

8. The President's Council on Substance Abuse Prevention (COSAP). Substance abuse prevention strategic plan, 2007-2011 Republic of Palau. 2006. Available at: https://untobaccocontrol.org/impldb/wp-content/uploads/ reports/Palau_annex4_national_strategic_plan.pdf. (Accessed August 2020).

9. College Enrollment Status: Percentages, 2014 and 2015. Available at: https:// www.samhsa.gov/data/sites/default/files/NSDUH-DetTabs-2015/NSDUHDetTabs-2015/NSDUH-DetTabs-2015.htm\#tab6-84b. (Accessed April 2017).

10. Office for National Statistics. Adult drinking habits in Great Britain: 2017. Available at: https://www.ons.gov.uk/peoplepopulationandcommunity/ healthandsocialcare/drugusealcoholandsmoking/datasets/ adultdrinkinghabits. (Accessed September 2020).

11. Behavioral Health Trends in the United States: Results from the 2014 National Survey on Drug Use and Health. Department of Health and Human Services, United States. 2015. Available at: https://www.samhsa.gov/ data/sites/default/files/NSDUH-FRR1-2014/NSDUH-FRR1-2014.pdf. (Accessed April 2017).

12. Republic of Palau, Ministry of Health. National Health Profile 2013. 2014. Available at: http://www.palauhealth.org/files/2013\%20National\%2 OHealth\%20Profile_\%20Final\%20121214.pdf. (Accessed August 2020).

13. Evans K. Prevention and control of alcohol and drug abuse: assignment report, 24 June to 21 July 1987. Wellington, New Zealand: World Health Organization; 1987.

14. Kessaram T, McKenzie J, Girin N, Roth A, Vivili P, Williams G, Hoy D. Alcohol use in the Pacific region: Results from the STEPwise approach to surveillance, Global School-Based Student Health Survey and Youth Risk Behavior Surveillance System. Drug Alcohol Rev. 2016:35:412-23.

15. Peltzer K, Pengpid S. Early substance use initiation and suicide ideation and attempts among school-aged adolescents in four pacific island countries in Oceania. Int J Environ Res Public Health. 2015;12:12291-303.
16. Lippe J, Brener N, Kann L, Kinchen S, Harris WA, McManus T, Speicher N Centers for Disease Control and Prevention (CDC). Youth risk behavior surveillance--Pacific Island United States Territories, 2007. MMWR Surveill Summ. 2008:57:28-56.

17. Daniel JZ, Hickman M, Macleod J, Wiles N, Lingford-Hughes A, Farrell M, Araya R, Skapinakis P, Haynes J, Lewis G. Is socioeconomic status in early life associated with drug use? A systematic review of the evidence. Drug Alcohol Rev. 2009;28:142-53.

18. Wiles NJ, Lingford-Hughes A, Daniel J, Hickman M, Farrell M, Macleod J, Haynes JC, Skapinakis P, Araya R, Lewis G. Socio-economic status in childhood and later alcohol use: a systematic review. Addiction. 2007;102: 1546-63.

19. Duncan TE, Duncan SC, Hops H. Latent variable modeling of longitudinal and multilevel alcohol use data. J Stud Alcohol. 1998;59:399-408.

20. Van Leijenhorst L, Westenberg PM, Crone EA. A developmental study of risky decisions on the cake gambling task: age and gender analyses of probability estimation and reward evaluation. Dev Neuropsychol. 2008;33: 179-96.

\section{Publisher's Note}

Springer Nature remains neutral with regard to jurisdictional claims in published maps and institutional affiliations.

\section{Ready to submit your research? Choose BMC and benefit from:}

- fast, convenient online submission

- thorough peer review by experienced researchers in your field

- rapid publication on acceptance

- support for research data, including large and complex data types

- gold Open Access which fosters wider collaboration and increased citations

- maximum visibility for your research: over $100 \mathrm{M}$ website views per year

At $\mathrm{BMC}$, research is always in progress.

Learn more biomedcentral.com/submissions 